\title{
2-Hydroxypropyl- $\beta$-Cyclodextrin Raises Hearing Threshold in Normal Cats and in Cats With Niemann-Pick Type C Disease
}

\author{
SARAH WARD, PATRICIA O'DONNELL, STEVEN FERNANDEZ, AND CHARLES H. VITE
}

Departments of Clinical Studies [S.W., C.H.V.] and Pathobiology [P.O., S.F.], School of Veterinary Medicine, University of Pennsylvania, Philadelphia, Pennsylvania 19104

\begin{abstract}
HP $\beta C D)$ is a promising experimental therapy for Niemann-Pick type $\mathrm{C}$ disease that improved intracellular cholesterol transport, substantially reduced neurodegeneration and hepatic disease, and increased lifespan in $\mathrm{npCl}^{-/-}$ mice. On the basis of favorable treatment outcome in mice, HP $\beta C D$ is being evaluated as a therapy in children with Niemann-Pick type $\mathrm{C}$ (NPC) disease. We evaluated the efficacy of $\mathrm{HP} \beta \mathrm{CD}$ in the feline model of NPC disease and recognized a dose-dependent increase in hearing threshold associated with therapy as determined by brain stem auditory evoked response (BAER) testing. To further assess the effect of HP $\beta C D$ on hearing threshold, normal cats were administered the drug s.c. at either $4000 \mathrm{mg} / \mathrm{kg}$ or $8000 \mathrm{mg} / \mathrm{kg}$ body weight, or intrathecally at a dose of $4000 \mathrm{mg} / \mathrm{kg}$ brain weight. HP $\beta C D$ caused a significant increase in hearing threshold following one dose of $8000 \mathrm{mg} / \mathrm{kg}$ s.c. or $120 \mathrm{mg}$ intrathecally, and the effect was maintained for at least 12 weeks. Repeated weekly s.c. administration of $4000 \mathrm{mg} / \mathrm{kg} \mathrm{HP} \beta C D$ resulted in a similar increase in hearing threshold. These studies are the first to describe a specific negative effect of $\mathrm{HP} \beta C D$ on the auditory system and suggest the need for auditory testing in patients receiving similar doses of HP $\beta C D$. (Pediatr Res 68: 52-56, 2010)
\end{abstract}

$\mathrm{C}$ yclodextrins are cyclic oligosaccharides with hydrophobic interiors used as formulation vehicles to increase the amount of drug, including hormones and vitamins, which can be solubilized in aqueous vehicles (1). 2-hydroxypropyl- $\beta$ cyclodextrin (HP $\beta C D$ ) was extensively studied in rodents, dogs, and monkeys where it was generally well tolerated at low doses $(1,2)$. Daily i.v. administration of greater than $200 \mathrm{mg} / \mathrm{kg}$ caused reduced body weight, foamy macrophage infiltration of the lungs, elevations in hepatic enzymes, increased Kuppfer cells in the liver, and renal cortical tubular vacuolization in rodents $(1,3,4)$. All of these changes were reversible following cessation of $\mathrm{HP} \beta C D$ administration (1).

Niemann-Pick type C (NPC) disease is an incurable lysosomal storage disorder characterized by the intralysosomal accumulation of unesterified cholesterol, hepatosplenomegaly, progressive neurologic dysfunction, and early death $(5,6)$. Weekly intraperitoneal administration of $1500 \mathrm{mg} / \mathrm{kg}$ of $\mathrm{HP} \beta C D$ to $n p c^{-1-}$ mice resulted in improvement in hepatic disease with no effect on neurologic disease or lifespan (7). In contrast, the administration of a single s.c. dose of $4000 \mathrm{mg} / \mathrm{kg}$ of a $20 \%$ solution of $\mathrm{HP} \beta \mathrm{CD}$

Received January 11, 2010; accepted March 7, 2010.

Correspondence: Charles H. Vite, D.V.M., Ph.D., Department of Clinical StudiesPhiladelphia, School of Veterinary Medicine, University of Pennsylvania, 3900 Delancey Street, Philadelphia, PA 19104; e-mail: vite@vet.upenn.edu

Supported by grants from the Ara Parseghian Medical Research Foundation, Dana's Angels Research Trust and NIH grant RR02512. to 7-d-old $n p c^{-1-}$ mice reversed the defect in the lysosomal transport of cholesterol and significantly improved hepatic dysfunction, decreased neurodegeneration, and prolonged lifespan (8). Every other day s.c. administration of $4000 \mathrm{mg} / \mathrm{kg}$ of a $20 \%$ solution of $\mathrm{HP} \beta \mathrm{CD}$ to $n p c^{-1-}$ mice was the most effective treatment regimen at ameliorating clinical disease and increasing lifespan, and also significantly decreased neuronal cholesterol, ganglioside, and sphingosine accumulation, and decreased neuroinflammation (9). It was hypothesized that high doses of $\mathrm{HP} \beta \mathrm{CD}$ were needed to ameliorate neurologic dysfunction because higher blood levels allowed more drug to cross the bloodbrain barrier. An alternative hypothesis was that increased serum levels of HP $\beta C D$ could bind enough circulating sterols to result in enhanced cholesterol egress from the CNS by an undefined mechanism (9). In each of these animal studies, no significant toxicity was observed after the administration of $\mathrm{HP} \beta C D$ except for increased macrophage infiltration of the lungs found at postmortem examination (9). On the basis of these data from the murine model, $\mathrm{HP} \beta \mathrm{CD}$ has been approved for use in a group of children with NPC disease by the Food and Drug Administration (FDA).

Naturally occurring NPC disease occurs in cats which have a mis-sense mutation in NPCl (2864G-C) with clinical, neuropathological, and biochemical abnormalities similar to those present in juvenile-onset patients making this model homologous to the most common form of the disease seen in human patients $(10,11)$. Brain stem auditory evoked response testing (BAER) of cats with NPC disease showed a prolongation in central conduction time with no significant alteration in hearing threshold compared with wild type cats (11). While evaluating the efficacy of $\mathrm{HP} \beta C D$ to treat NPC disease in cats, we noted a significant elevation of hearing threshold in animals receiving repeated s.c. doses of $4000 \mathrm{mg} / \mathrm{kg}$. To our knowledge, a negative effect of $\mathrm{HP} \beta C D$ on auditory function has not been evaluated in any species. This study investigated the effects of the s.c. and intrathecal administration of $\mathrm{HP} \beta C D$ treatment on the BAER of both normal cats and cats with NPC disease.

\section{METHODS}

Animals. Cats were raised in the animal colony of the School of Veterinary Medicine, University of Pennsylvania, under National Institutes of Health and USDA guidelines for the care and use of animals in research. The experi-

Abbreviations: BAER, brain stem auditory evoked response; HP $\boldsymbol{\beta C D}$, hydroxypropyl-beta-cyclodextrin; NPC, Niemann-Pick type C 
mental protocol was approved by the University of Pennsylvania Institutional Animal Care and Use Committee.

All animals examined were produced from the same line bred to produce cats with autosomal recessively inherited Niemann-Pick type C (NPC) disease. All cats were housed at $21^{\circ} \mathrm{C}$ with ad libitum food and water, 12-h light cycles, with 12-15 air changes per hour. Peripheral blood leukocytes from all cats were tested at 1 day of age for the NPC1 mis-sense mutation using a PCR-based DNA test (10). Cats with two copies of the mis-sense mutation were classified as affected with NPC disease while cats with one or no copies of the mutation were classified as normal. Heterozygote to heterozygote breedings produced $\sim 25 \%$ affected and $\sim 75 \%$ normal offspring.

Study groups. Normal cats were placed in one of five study groups (Table 1). Group $1(n=7)$ were 6 months old and received no drug. Group $2(n=$ 3) received one dose of $4000 \mathrm{mg} / \mathrm{kg}$ body weight HP $\beta C D$ s.c. at 6 months of age. Group $3(n=3)$ received one dose of $8000 \mathrm{mg} / \mathrm{kg}$ body weight HP $\beta C D$ s.c. at 6 months of age. Group $4(n=3)$ received one dose of $4000 \mathrm{mg} / \mathrm{kg}$ brain weight (120 mg for a 30-g brain weight) $\mathrm{HP} \beta C D$ intrathecally at 6 months of age. Intrathecal adminstration was achieved by anesthetizing cats with i.v. propofol (up to $6 \mathrm{mg} / \mathrm{kg}$; Abbott Laboratories, Chicago, IL). A 20-gauge spinal needle was placed into the cerebellomedullary cistern and 1.0 $\mathrm{mL}$ of spinal fluid was removed. $0.6 \mathrm{~mL}$ of $20 \% \mathrm{HP} \beta \mathrm{CD}$ in saline was injected intrathecally over a 2 -minute time period into the cerebellomedullary cistern. Group $5(n=3)$ received weekly $4000 \mathrm{mg} / \mathrm{kg}$ body weight HP $\beta C D$ s.c. beginning at 8 weeks of age for a total of seven doses.

Cats affected with NPC disease were already involved in a clinical study evaluating the efficacy of $\mathrm{HP} \beta C D$ to treat disease. All cats were first administered the drug at 3 weeks of age, before the onset of clinical signs of disease, and continued to receive the drug weekly thereafter. Cats were placed into one of five groups (Table 2). Group $6(n=8)$ received no HP $\beta C D$ and served as the control group for cats with NPC disease. Groups $7(n=5), 8(n=2)$, and $9(n=5)$ received a weekly dose of $1000 \mathrm{mg} / \mathrm{kg}$ HP $\beta C D$ body weight s.c., $4000 \mathrm{mg} / \mathrm{kg}$ body weight HP $\beta C D$ s.c., and $8000 \mathrm{mg} / \mathrm{kg}$ body weight HP $\beta C D$ s.c., respectively. Group $10(n=2)$ received $4000 \mathrm{mg} / \mathrm{kg}$ brain weight (120 $\mathrm{mg}$ for a $30 \mathrm{-g}$ brain weight) $\mathrm{HP} \beta \mathrm{CD}$ intrathecally every $2 \mathrm{wk}$ (intrathecal administration methods described earlier).

$\boldsymbol{H P} \boldsymbol{\beta C D}$ formulations. All HP $\beta \mathrm{CD}$ was administered in a $20 \%$ (wt/vol) solution dissolved in $0.9 \%$ sodium chloride. HP $\beta C D$ was received from Sigma Chemical Co. and the powdered form (HP $\beta C D-H 107$; Sigma Chemical Co. Aldrich, St. Louis, MO) was used in all s.c. administrations and the cell culture tested form (HP $\beta$ CD-C0926; Sigma Chemical Co. Aldrich) was used for all intrathecal administrations. As a control for the saline injection, additional normal cats were injected one time s.c. $(n=2)$ and intrathecally $(n=2)$ with similar volumes of saline.

To control for possible differences between HP $\beta C D$ available from Sigma Chemical Co., the product used in published mouse studies $(8,9)$ and the FDA-approved formulation for use in patients (Trappsol-Pharm grade, Cyclodextrin Technologies Development, Inc, High Springs, FL), Trappsol was administered to four cats: one dose of $8000 \mathrm{mg} / \mathrm{kg}$ body weight s.c. $(n=2)$ and one dose of $4000 \mathrm{mg} / \mathrm{kg}$ brain weight intrathecally (120 mg for a 30-g brain weight; $n=2$ ).

Brain stem auditory evoked response testing. All measurements of the BAER were obtained from cats given atropine sulfate $(0.02 \mathrm{mg} / \mathrm{kg}$; Butler Animal Health Supply, Dublin, $\mathrm{OH}$ ) and then anesthetized with i.v. propofol (up to 6 $\mathrm{mg} / \mathrm{kg}$ ). The BAER data were recorded using $12 \mathrm{~mm}, 29$-gauge subdermal needle electrodes and a Nicolet Viking Quest signal analyzer (Nicolet Biomedical, Madison, WI). The active electrode was placed over the osseous bulla of the stimulated ear, the reference electrode was situated over the vertex of the skull, and the ground electrode over the contralateral osseous bulla. All recording electrodes were placed s.c. Alternating rarefaction and condensation clicks were produced by connecting a square wave pulse $(0.1 \mathrm{~ms}$ in duration) to a speaker (Model TIP-300; Nicolet Biomedical, Madison, WI). The stimuli were presented monaurally at a rate of $11.1 \mathrm{~Hz}$ using a $25-\mathrm{cm}$ plastic tube of $1.5 \mathrm{~mm}$ diameter which was connected to the speaker at one end, with the other end laid in the unsealed ear canal (an open field stimulus). The stimulator delivered a $125 \mathrm{~dB}$

Table 1. Summary of groups of normal cats treated with $H P \beta C D$

\begin{tabular}{ccl}
\hline Group & No. of cats & Dose and method of administration of $\mathrm{HP} \beta \mathrm{CD}$ \\
\hline 1 & 7 & NA \\
2 & 3 & $4000 \mathrm{mg} / \mathrm{kg}$ body weight subcutaneously once \\
3 & 3 & $8000 \mathrm{mg} / \mathrm{kg}$ body weight subcutaneously once \\
4 & 3 & $4000 \mathrm{mg} / \mathrm{kg}$ brain weight intrathecally once \\
5 & 3 & $\begin{array}{c}4000 \mathrm{mg} / \mathrm{kg} \text { body weight subcutaneously } \\
\text { weekly for 7 doses }\end{array}$ \\
\end{tabular}

NA, not applicable.
Table 2. Summary of groups of cats with NPC disease treated with $H P \beta C D$

\begin{tabular}{ccl}
\hline Group & No. of cats & Dose and method of administration of HP $\beta C D$ \\
\hline 6 & 8 & NA \\
7 & 5 & $1000 \mathrm{mg} / \mathrm{kg}$ body weight subcutaneously weekly \\
8 & 2 & $4000 \mathrm{mg} / \mathrm{kg}$ body weight subcutaneously weekly \\
9 & 5 & $8000 \mathrm{mg} / \mathrm{kg}$ body weight subcutaneously weekly \\
10 & 2 & to00 $\mathrm{mg} / \mathrm{kg}$ brain weight intrathecally every \\
& & two weeks
\end{tabular}

NA, not applicable.

pSPL click to the recorded ear and delivered an $85 \mathrm{~dB}$ SPL white noise to the contralateral ear. The high pass filter on the amplifier was $20 \mathrm{~Hz}$ and the low pass cutoff was $3 \mathrm{kHz}$. A sensitivity of $1 \mathrm{uV} / \mathrm{cm}$ was used to record the responses and the averaging epoch was $10 \mathrm{~ms}$ with a sampling resolution of $0.01 \mathrm{~ms}$. One thousand evoked responses were averaged for each BAER response obtained. Central conduction time was defined as the time between the first and the fifth peak. Wave V/I amplitude was determined by dividing the amplitude of the fifth wave by the amplitude of the first wave and multiplying by 100; amplitude was measured from peak to trough and expressed as microvolts. A modified method of limit procedure was used to estimate threshold. When a clearly defined BAER was identified at the reference stimulus of $125 \mathrm{~dB}$, the attenuator was then increased in $3 \mathrm{~dB}$ steps and a signal averaged response was sought at each step. If an evoked response was observed, the attenuator was then increased by another $3 \mathrm{~dB}$ and the BAER response again observed. This continued until a sound level was reached at which an averaged evoked response could not be identified.

In normal cats, BAER studies were performed every other week following the administration of $\mathrm{HP} \beta C \mathrm{C}$ in groups 2,3 , and 4 for a total of $12 \mathrm{wk}$, and were performed every week in group 5 for a total of 12 wk. In cats with NPC disease, BAER studies were performed at 16 weeks of age.

Statistical methods. The mean and SD of the thereshold, central conduction time, and wave V/I ratio estimates in each group were calculated to describe the data and an unpaired 2-tailed $t$ test was used to compare data between various groups. Significance values of $p<0.05(*)$ are given. Threshold differences between groups were considered statistically reliable if the probability of chance occurrence was 0.05 or less.

\section{RESULTS}

Normal cats. None of the normal animals that received either s.c. or intrathecal HP $\beta C D$ injections showed evidence of loss of balance or ataxia at any point during the study. No clinical signs were attributable to $\mathrm{HP} \beta \mathrm{CD}$ administration aside from pain at the s.c. injection site which was common in cats receiving weekly doses. Subjective evaluation of hearing was difficult to perform because normal, untreated colonybred animals frequently do not respond repeatably to sound. Detailed behavioral testing was not performed.

A single s.c. dose of $4000 \mathrm{mg} / \mathrm{kg} \mathrm{HP} \beta \mathrm{CD}$ evoked waveforms the same as in cats which received no HP $\beta C D$ (Fig. 1, groups 1 and 2). In contrast, a single s.c. dose of $8000 \mathrm{mg} / \mathrm{kg}$ $\mathrm{HP} \beta C D$ resulted in diminished wave form amplitude with changes severe enough to make specific waveforms difficult to identify (Fig. 1, group 3). Similarly, a single intrathecal dose of $120 \mathrm{mg} \mathrm{HP} \beta \mathrm{CD}$ resulted in altered evoked responses characterized by reduced amplitude (Fig. 1, group 4). A single injection of intrathecal saline left the BAER unchanged in two cats (data not shown).

Hearing threshold, wave V/I amplitude, and central conduction time were measured for groups 1-5 (Table 3). Cats in groups 3 and 4 showed a significant increase in hearing threshold 2 weeks after injection compared with uninjected cats (group 1). The average click BAER threshold in control cats was $66 \mathrm{~dB}$, whereas in groups 3 and 4 that were treated with $4000 \mathrm{mg} / \mathrm{kg}$ and $8000 \mathrm{mg} / \mathrm{kg} \mathrm{HP} \beta \mathrm{CD}$, repectively, the 


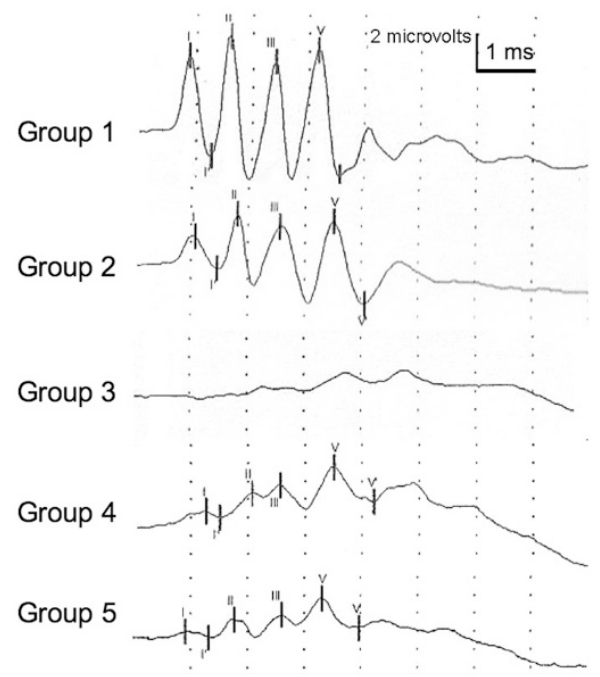

Figure 1. Representative brainstem auditory evoked responses for normal cats following the administration of $\mathrm{HP} \beta \mathrm{CD}$ (group 2-5). Recordings for groups $2-4$ were made 2 weeks after a administering a single drug dose. The recording for Group 5 was made one week after the sixth weekly drug dose. A decrease in wave form amplitude was noted in groups 3, 4, and 5 compared with untreated cats (group 1). Changes in groups 3-5 were severe enough that waveforms could not always be reliably identified (an example is given for group 3).

Table 3. Hearing threshold, wave V/I amplitude, and central conduction time 2 weeks after administering a single dose of $H P \beta C D$ to normal cats (groups 2-4) and 1 wk after the sixth dose (group 5)

\begin{tabular}{lccc}
\hline & $\begin{array}{c}\text { Hearing threshold } \\
(\mathrm{dB} \mathrm{SPL})\end{array}$ & $\begin{array}{c}\text { Wave V/I } \\
\text { amplitude }\end{array}$ & $\begin{array}{c}\text { Central conduction } \\
\text { time }(\mathrm{ms})\end{array}$ \\
\hline Group 1 $(n=7)$ & $66.4 \pm 3.2$ & $181 \pm 16.7$ & $2.41 \pm 0.09$ \\
Group 2 $(n=3)$ & $63.0 \pm 5.2$ & $212 \pm 24.0$ & $2.43 \pm 0.02$ \\
Group 3 $(n=3)$ & $79.0 \pm 4.6^{*}$ & $545 \pm 402$ & $2.36 \pm 0.02$ \\
Group 4 $(n=3)$ & $81.0 \pm 3.0^{*}$ & $525 \pm 127$ & $2.37 \pm 0.05$ \\
Group 5 (six doses & $80.0 \pm 1.7^{*}$ & $469 \pm 423$ & $2.38 \pm 0.09$ \\
$\quad$ of HPBCD) $(n=3)$ & & & \\
\hline
\end{tabular}

$* p<0.05$.

threshold increased to 79 and $81 \mathrm{~dB}$, respectively. This approximately $13 \mathrm{~dB}$ difference between groups was statistically reliable $(p<0.05)$. Differences in wave V/I amplitude or in central conduction time were due to random sampling and were statistically insignificant among the groups. The BAER of cats in groups 2, 3, and 4 remained unchanged, neither improving nor worsening, during the 12-wk study following a single administration of HP $\beta C D$ (data not shown).

Cats in group 5 received 7 weekly injections of $4000 \mathrm{mg} / \mathrm{kg}$ $\mathrm{HP} \beta C D$ s.c. Interestingly, although these cats showed no significant elevation in hearing threshold 2 weeks after the first injection, repeated weekly injections of the same dose resulted in a progressive elevation of hearing threshold with the threshold on the fourth through seventh week significantly greater than the hearing threshold observed before injection (week 0) (Table 3; Fig. 2).

Cats with NPC disease. Affected cats began weekly s.c. therapy with $\mathrm{HP} \beta C D$ at 3 weeks of age in an attempt to ameliorate disease progression. At $16 \mathrm{wk}$ of age, hearing thresholds were statistically the same in normal cats (group 1, 66.4 dB $\pm 3 / 2$

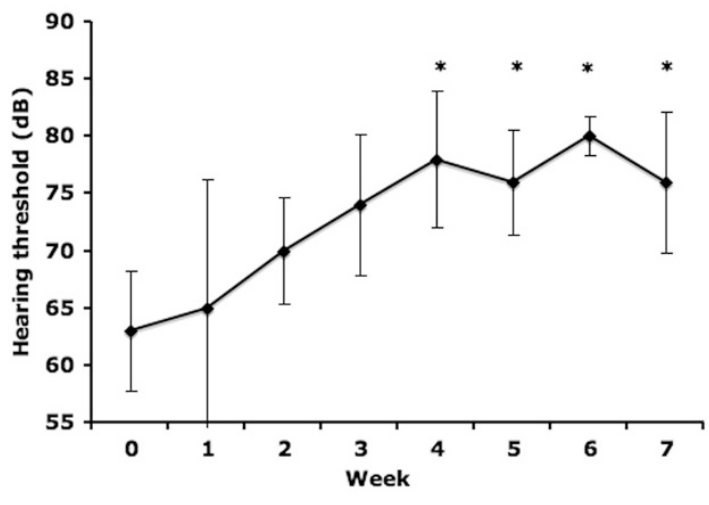

Figure 2. Weekly hearing thresholds following $4000 \mathrm{mg} / \mathrm{kg}$ weekly $\mathrm{HP} \beta \mathrm{CD}$ administration (group $5 ; n=3$ ). The first dose was administered immediately after Week 0 threshold testing. Repeated $\mathrm{HP} \beta C D$ administration resulted in progressive elevation of the hearing threshold with a statistically significant $(p<0.05)$ increase from weeks 4 to 7 when compared with week 0.

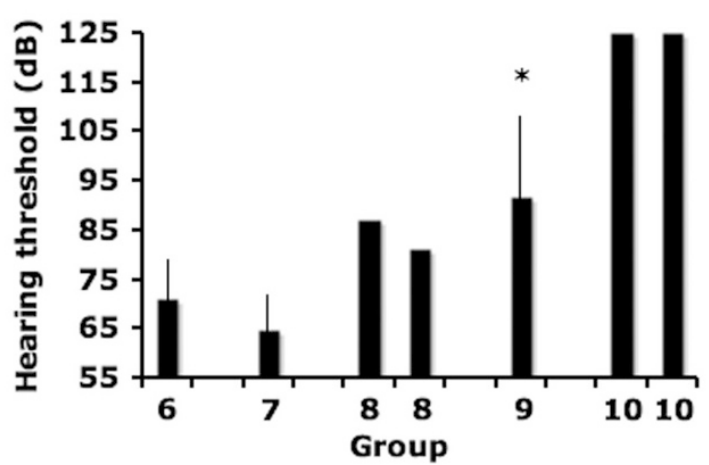

Figure 3. Cats with NPC disease cats showed no increase in hearing threshold after weekly administration of $1000 \mathrm{mg} / \mathrm{kg} \operatorname{HP} \beta C D$ (group 7; $n=5$ ) compared with untreated affected cats (group $6 ; n=8$ ). Both cats treated with weekly $4000 \mathrm{mg} / \mathrm{kg}$ (group $8 ; n=2$ ) showed an increase in hearing threshold and cats treated with weekly $8000 \mathrm{mg} / \mathrm{kg}$ (group $9 ; n=5$ ) had a statistically significant $(p<0.05)$ increase in threshold. No waveforms were evoked at the maximum stimulus intensity of $125 \mathrm{~dB}$ from two cats treated with every other week intrathecal HPBCD (group 10).

$\mathrm{dB}$ ) and cats with NPC disease (group 6, $71.9 \mathrm{~dB} \pm 7.9 \mathrm{~dB}$ ). Interestingly, significant differences were absent between cats treated s.c. with $1000 \mathrm{mg} / \mathrm{kg} \mathrm{HP} \beta \mathrm{CD}(65 \mathrm{~dB} \pm 7.5 \mathrm{~dB}$; group 7) and untreated cats (group 6) (Fig. 3). However, both animals treated with weekly s.c. administered $4000 \mathrm{mg} / \mathrm{kg}$ (group 8) had higher hearing thresholds than any untreated cats with NPC disease. Similarly, cats treated with weekly s.c. administered $8000 \mathrm{mg} / \mathrm{kg}(91.8 \mathrm{~dB} \pm 16.4 \mathrm{~dB}$; group 9) had significantly greater hearing threshold compared with untreated cats with NPC disease. Finally, both cats given HP $\beta C D$ intrathecally (every other week) had no click evoked waveforms even at the highest sound intensity of $125 \mathrm{~dB}$. Where waveforms could be reliable discerned, the wave V/I amplitude and the central conduction time did not differ between untreated cats with NPC disease and cats treated with $\mathrm{HP} \beta C D$.

Normal cats receiving trappsol. Trappsol was administered s.c. to two normal cats as a single dose of $8000 \mathrm{mg} / \mathrm{kg}$ body weight and intrathecally to two normal cats as a single dose of $4000 \mathrm{mg} / \mathrm{kg}$ brain weight (120 mg for a $30 \mathrm{-g}$ brain weight) in the same manner as the Sigma Chemical Co. product was 
A
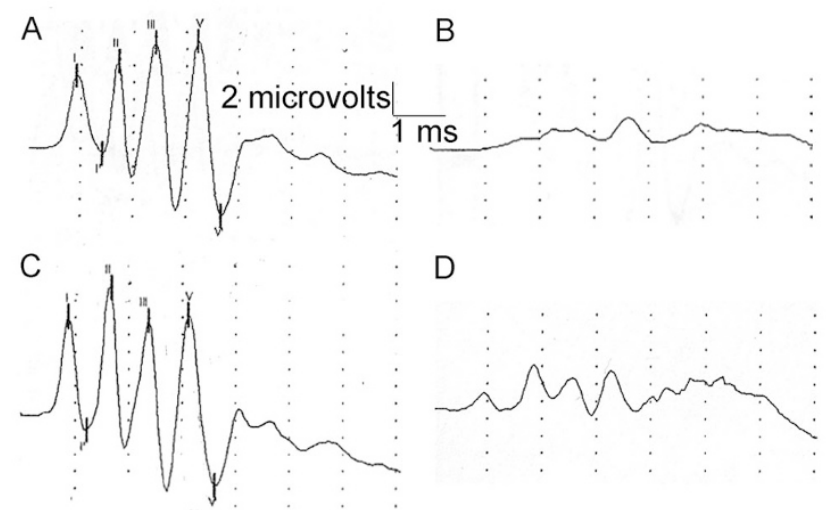

Figure 4. Normal cats treated with either intrathecal or s.c. Trappsol showed abnormal waveforms 1 week after administration. A, shows BAER tracing immediately before intrathecal injection of $120 \mathrm{mg}$ Trappsol; $B$, shows BAER in same cat 1 week later. $C$, shows BAER tracing immediately before s.c. injection of $8000 \mathrm{mg} / \mathrm{kg}$ Trappsol; $D$, shows BAER in same cat 1 week later.

administered. BAER recordings were first made within $15 \mathrm{~min}$ of s.c. and intrathecal administration and no changes in the waveforms were noted (data not shown). Figure $4 A$ and $C$ show the BAER recordings before Trappsol administration in two cats. Figure $4 B$ shows the BAER recording 1 week after the administration of HP $\beta C D$ intrathecally, and Figure $4 D$ shows the tracing obtained 1 week after the administration of s.c. HP $\beta C D$. The administration of Trappsol to normal cats resulted in changes to the BAER similar to that seen with the Sigma Chemical Co. product. Hearing threshold in two cats treated intrathecally increased from $69 \mathrm{~dB}$ to $72 \mathrm{~dB}$ before drug administration to $87 \mathrm{~dB}$ and $90 \mathrm{~dB}$ following administration. Hearing threshold in two cats treated s.c. increased from $69 \mathrm{~dB}$ and $72 \mathrm{~dB}$ before drug administration, to $87 \mathrm{~dB}$ in both cats following drug administration.

\section{DISCUSSION}

Niemann-Pick type $\mathrm{C}$ disease has an incidence of 1:150,000, with $>250$ disease-causing mutations identified (5). Natural history studies and therapy trials are difficult to perform on this disorder because of the relatively low incidence and the heterogeneity of disease in human patients. One particular mis-sense mutation represents $>20 \%$ of mutant alleles and $>50 \%$ of patients have a juvenile onset of neurologic disease. The feline model of NPC disease has a spontaneously occurring mis-sense mutation in NPCl (2864G-C) and exhibits clinical, neuropathological, and biochemical abnormalities similar to those present in juvenile-onset patients. Thus the cat model is homologous to the most common form of disease seen in human patients $(10,12-17)$. The feline model has been useful for identifying the late endosomal/lysosomal accumulation of unesterified cholesterol and gangliosides (GM2 and GM3) (18), for evaluating the association of GM2 storage with meganeurite formation and abnormal dendritogenesis (19), for correlating neuroaxonal dystrophy with neurologic dysfunction (16), and for evaluating efficacy of experimental therapies $(13,19)$. The onset and progression of neurologic dysfunction in the feline model has been well characterized $(11,15)$. A regular onset of progressive cerebellar and vestibular dysfunction occurred in affected cats beginning with intention tremors and ataxia at 6 weeks of age. This dysfunction progressed until cats could no longer maintain sternal recumbency at $\sim 24$ wk of age. Changes in hearing threshold were not found although a delay in central conduction time and a decrease in wave V/I amplitude ratio was observed in 16- and 24-wk old affected cats compared with wild type cats (11).

HP $\beta C D$ are cyclic oligosaccharides consisting of seven $\beta$ (1-4) glucopyranose units (7). HP $\beta C D$ s have a hydrophilic exterior and a hydrophobic interior making them useful for increasing the aqueous solubility of hydrophobic molecules such as cholesterol, steroids, and vitamins (20). In vitro studies using $\beta$-cyclodextrins have shown a marked removal of cholesterol from cultured neuronal $(21,22)$ and nonneuronal cell lines (23-25). HP $\beta$ CDs were shown to cross the blood brain barrier in in vitro (25) and in in vivo with difficulty $(7,26)$. However, $\beta$-cyclodextrins were safely administered intrathecally in rodent studies and used to improve the delivery to the brain of drugs including anesthetic agents, galaninlike peptide, and estradiol (27-29).

Recently, HP $\beta C D$ was shown to release cholesterol from NPC-deficient lysosomes and allowed unesterified cholesterol to be available to the NPC cell. This resulted in the amelioration of disease and the prolongation of life in the murine model $(8,9,30)$. However, high doses of $\mathrm{HP} \beta C D$ (at least $4000 \mathrm{mg} / \mathrm{kg}$ weekly) appeared necessary to retard the progression of neurologic disease. Studies in $n p c 1^{-1-}$ mice showed that $1500 \mathrm{mg} / \mathrm{kg} \mathrm{HP} \beta \mathrm{CD}$ administered weekly caused a decrease in hepatic unesterified cholesterol concentrations without substantial effect on neurologic signs (7). Increasing the dose to either $4000 \mathrm{mg} / \mathrm{kg}$ weekly or every other day delayed clinical disease onset, increased survival time, corrected cholesterol metabolism, and improved biochemical and histologic disease $(8,9)$. Because $\beta$-cyclodextrins do not easily penetrate the blood brain barrier $(7,25)$, these studies suggested that parenteral administration of high doses of $\mathrm{HP} \beta C D$ are necessary to get sufficient amounts of HP $\beta C D$ to cross the blood brain barrier and to have an effect on neurologic disease. Unfortunately, the pharmacokinetics of $\mathrm{HP} \beta C D$ are not well understood particularly in the nervous system. A plasma elimination half-life in rats was $0.4 \mathrm{~h}$ and in dogs was $0.8 \mathrm{~h}$, although the concentration in cerebrospinal fluid after systemic administration was not described (1). Serum and cerebrospinal measurements of unlabeled $\mathrm{HP} \beta \mathrm{CD}$ are technically difficult to perform, and these concentrations were not determined in the recent murine articles $(8,9,30)$. Clearly, the kinetics of $\mathrm{HP} \beta C D$ in serum and spinal fluid will be necessary to clarify how HP $\beta C D$ s effect neurologic dysfunction in NPC disease and to determine what dose is most efficacious while also limiting toxicity.

As a result of the dramatic improvement in clinical signs seen in the mouse model of NPC disease, $\mathrm{HP} \beta \mathrm{CD}$ was given recent FDA approval for use in a small number of patients with NPC disease. This has increased the urgency to more fully characterize any dose-related potential toxic effects of the drug. In humans, i.v. administration of up to $3 \mathrm{~g}$ in healthy volunteers was well tolerated and doses of $16 \mathrm{~g}$ per day given with itraconazole did not result in hearing abnormalities (4). The authors could not find examples of doses of $1000 \mathrm{mg} / \mathrm{kg}$ and higher being used in human patients, although these are being proposed to treat patients with NPC disease. The authors are aware of no previous 
study examining the effect of $\mathrm{HP} \beta \mathrm{CD}$ on auditory function and yet we were able to determine an effect on hearing using a small number of normal cats and cats with NPC disease. Our data show that $1000 \mathrm{mg} / \mathrm{kg}$ had no effect on the BAER response when given weekly for 14 doses between the ages of 3 and 16 wk of age. Doses of $4000 \mathrm{mg} / \mathrm{kg}$ body weight resulted in an increase in hearing threshold only after repeated dosing and doses of 8000 $\mathrm{mg} / \mathrm{kg}$ body weight resulted in significant increases in hearing threshold in both normal cats and cats with NPC disease following the administration of a single dose. Interestingly, the doses needed to negatively impact the BAER response were the same dose necessary to retard nervous system dysfunction in mice. Our preliminary data in cats affected with NPC disease suggest a similar requirement for doses equal to or $>4000 \mathrm{mg} / \mathrm{kg}$ to positively affect neurologic disease (data not shown). One conclusion that suggested itself is that doses of $>4000 \mathrm{mg} / \mathrm{kg}$ are necessary for $\mathrm{HP} \beta C D$ to cross the blood brain barrier and that the effect on hearing is related to the ability of the drug to enter the CNS. Our data on the effect of intrathecal administration of $\mathrm{HP} \beta \mathrm{CD}$ on hearing threshold supported the conclusion that the drug had its negative effect on hearing only after it entered the spinal fluid. Importantly, whether the drug was given s.c. or intrathecally, the negative effect of $\mathrm{HP} \beta \mathrm{CD}$ on the auditory system was not ameliorated up to 12 wk after the cessation of drug administration suggesting that the effects may be irreversible.

The increased hearing threshold with no change in central conduction time suggested that the damage from HP $\beta C D$ occurred in the peripheral auditory pathway (cochlea or eighth nerve) and that potential mechanisms of action for the hearing loss observed include a direct effect on the stria vascularis and its role in maintaining the ionic environment of the inner ear fluid space, the transduction and motility mechanisms of inner and outer hair cells, and/or the excitation patterns in the auditory nerve discharges. Identifying the site of action of $\mathrm{HP} \beta C D$ within the peripheral auditory system will likely be the first step in overcoming toxicity of $\mathrm{HP} \beta C \mathrm{C}$ applications. Otoacoustic emission testing would be a useful method for evaluating outer hair cell function in cats but was unavailable for these studies. Histopathology of the cochlea should be performed in the future to identify any pathologic changes.

In summary, hearing impairment following $\mathrm{HP} \beta C D$ administration appeared to be both dose dependent and long lasting and may be a limiting factor in the use of this drug at high doses to treat Niemann-Pick type $\mathrm{C}$ disease. Auditory testing is recommended for patients receiving doses of $4000 \mathrm{mg} / \mathrm{kg} \mathrm{HP} \beta \mathrm{CD}$ or greater to evaluate the effect on hearing threshold in these patients.

Acknowledgments. We acknowledge the critical review of the manuscript by Drs. Shel Steinberg and James Saunders. Trappsol was provided by Dr. Rick Stratton.

\section{REFERENCES}

1. Gould S, Scott R 2005 2-Hydroxypropyl-beta-cyclodextrin (HPBCD): a toxicological review. Food Chem Toxicol 43:1451-1459
2. Brewster ME, Anderson WR, Meinsma D, Moreno D, Webb AI, Pablo L, Estes KS, Derendorf H, Bodor N, Sawchuk R, Cheung B, Pop E 1997 Intravneous and oral pharmakinetic evaluation of a 2-hydroxypropyl- $\beta$-cyclodextrin-based formulation of carbamazepine in the dog: comparison with commercially available tablets and suspensions. J Pharm Sci 86:335-339

3. Irie T, Uekama K 1997 Pharmaceutical applications of cyclodextrins. III. Toxicological issues and safety evaluation. J Pharm Sci 86:147-162

4. Stella VJ, He Q 2008 Cyclodextrins. Toxicol Pathol 36:30-42

5. Vanier MT, Millat G 2003 Niemann-Pick disease type C. Clin Genet 64:269-281

6. Patterson MC, Vanier MT, Suzuki K, Morris JA, Carstea E, Neufeld EB Blanchette, Mackie EJ, Pentchev PG 2001 Niemann-Pick disease type C: a lipid trafficking disorder. In: Valle D, Beaudet AL, Vogelstein B, Kinzler KW, Antonarakis SE, Ballabio A (eds) Metabolic and Molecular Bases of Inherited Disease. 8th ed. McGraw-Hill Companies, New York. Available at: http://www.ommbid.com. Accessed March 23, 2010

7. Camargo F, Erickson RP, Garver WS, Hossain GS, Carbone PN, Heidenreich RA, Blanchard J 2001 Cyclodextrins in the treatment of a mouse model of Niemann-Pick C disease. Life Sci 70:131-142

8. Liu B, Turley SD, Burns DK, Miller AM, Repa JJ, Dietschy JM 2009 Reversal of defective lysosomal transport in NPC ameliorates liver dysfunction and neurodegeneration in $\mathrm{npc}^{-1-}$ mouse. Proc Natl Acad Sci USA 106:2377-2382

9. Davidson CD, Ali NF, Micsenyi MC, Stephney G, Renault S, Dobrenis K, Ory DS, Vanier MT, Walkley SU 2009 Chronic cyclodextrin treatment of murine NiemannPick C disease ameliorates neuronal cholesterol and glycosphingolipid storage and disease progression. PLoS One 4:e6951

10. Somers KL, Royals MA, Carstea ED, Rafi MA, Wegner DA, Thrall MA 2003 Mutation analysis of feline Niemann-Pick C1 disease. Mol Genet Metab 79:99-103

11. Vite CH, Ding W, Bryan C, O'Donnell P, Cullen K, Aleman D, Haskins ME, Van Winkle T 2008 Clinical, electrophysiological, and serum biochemical measures of progressive neurological and hepatic dysfunction in feline Niemann-Pick type C disease. Pediatr Res 64:544-549

12. Lowenthal AC, Cummings JF, Wenger DA, Thrall MA, Wood PA, de Lahunta A 1990 Feline sphingolipidosis resembling Niemann-Pick disease type C. Acta Neuropathol 81:189-197

13. Somers KL, Brown DE, Fulton R, Schultheiss PC, Hamar D, Smith MO, Allison R, Connally HE, Just C, Mitchell TW, Wenger DA, Thrall MA 2001 Effects of dietary cholesterol restriction in a feline model of Niemann-Pick type $\mathrm{C}$ disease. J Inherit Metab Dis 24:427-436

14. Brown DE, Thrall MA, Walkley SU, Wenger DA, Mitchell TW, Smith MO, Royals KL, March PA, Allison RW 1994 Feline Niemann-Pick disease type C. Am J Pathol $144: 1412-1415$

15. Munana KR, Luttgen PJ, Thrall MA, Mitchell TW, Wenger DA 1994 Neurological manifestations of Niemann-Pick disease type C in cats. J Vet Intern Med 8:117-121

16. March PA, Thrall MA, Brown DE, Mitchell TW, Lowenthal AC, Walkley SU 1997 GABAergic neuroaxonal dystrophy and other cytopathological alterations in feline Niemann-Pick disease type C. Acta Neuropathol 94:164-172

17. Zervas M, Dobrenis K, Walkley SU 2001 Neurons in Niemann-Pick disease type C accumulate gangliosides as well as unesterified cholesterol and undergo dendritic and axonal alterations. J Neuropathol Exp Neurol 60:49-64

18. Walkley SU, Suzuki K 2004 Consequences of NPC1 and NPC2 loss of function in mammalian neurons. Biochim Biophys Acta 1685:48-62

19. Zervas M, Somers KL, Thrall MA, Walkley SU 2001 Critical role for glycosphingolipids in Niemann-Pick disease type C. Curr Biol 11:1283-1287

20. Ferezou J, Riottot M, Serougne C, Cohen-Solal C, Catala I, Alquier C, Parquet M, Juste C, Lafont H, Mathe D, Corring T, Lutton C 1997 Hypocholesterolemic action of beta-cyclodextrin and its effects on cholesterol metabolism in pigs fed a cholesterol-enriched diet. J Lipid Res 38:86-100

21. Huang P, Xu W, Yoon SI, Chen C, Chong PL, Liu-Chen LY 2007 Cholesterol reduction by methyl-beta-cyclodextrin attenuates the delta opioid receptor-mediated signaling in neuronal cells but enhances it in non-neuronal cells. Biochem Pharmacol 73:534-549

22. Bar-On P, Rockenstein E, Adame A, Ho G, Hashimoto M, Masliah E 2006 Effects of the cholesterol-lowering compound methyl-beta-cyclodextrin in models of alphasynucleinopathy. J Neurochem 98:1032-1045

23. Ohtani Y, Irie T, Uekama K, Fukunaga K, Pitha J 1989 Differential effects of alpha-, beta- and gamma-cyclodextrins on human erythrocytes. Eur J Biochem 186:17-22

24. Klein U, Gimpl G, Fahrenholz F 1995 Alteration of the myometrial plasma membrane cholesterol content with beta-cyclodextrin modulates the binding affinity of the oxytocin receptor. Biochemistry 34:13784-13793

25. Monnaert V, Tilloy S, Bricout H, Fenart L, Cecchelli R, Monflier E 2004 Behavior of alpha-, beta-, and gamma-cyclodextrins and their derivatives on an in vitro model of blood-brain barrier. J Pharmacol Exp Ther 310:745-751

26. Pitha J, Irie T, Sklar PB, Nye JS 1988 Drug solubilizers to aid pharmacologists: amorphous cyclodextrin derivatives. Life Sci 43:493-502

27. Pitha J, Gerloczy A, Olivi A 1994 Parenteral hydroxypropyl cyclodextrins: intravenous and intracerebral administration of lipophiles. J Pharm Sci 83:833-837

28. Wang X, He H, Leng W, Tang X 2006 Evaluation of brain-targeting for the nasal delivery of estradiol by the microdialysis method. Int J Pharm 317:40-46

29. Nonaka N, Farr SA, Kageyama H, Shioda S, Banks WA 2008 Delivery of galaninlike peptide to the brain: targeting with intranasal delivery and cyclodextrins. J Pharmacol Exp Ther 325:513-519

30. Abi-Mosleh L, Infante RE, Radhakrishnan A, Goldstein JL, Brown MS 2009 Cyclodextrin overcomes deficient lysosome-to-endoplasmic reticulum transport of cholesterol in Niemann-Pick type C cells. Proc Natl Acad Sci USA 106:1931619321 